\title{
De los lugares de espera a los territorios de la espera. ¿Una nueva dimensión de la geografía social?
}

\author{
Alain Musset \\ École des Hautes Études en Sciences Sociales (EHESS) \\ Centre de Recherches Historiques (CRH) \\ Groupe de Géographie et d'Histoire, de l'Environnement, des Ressources et des Sociétés \\ (GGH-TERRES) \\ musset@ehess.fr
}

\section{Resumen}

Lejos de ser fluidos, homogéneos o lineales, los desplazamientos de distinta índole que caracterizan a las sociedades contemporáneas están marcados por tiempos y momentos, más o menos largos, de espera. El propósito de este artículo es analizar cómo y por qué tales momentos encuentran una traducción espacial relacionada con interacciones sociales específicas. Rebasar la noción tradicional de «lugares de espera» para configurar nuevos "territorios de la espera» nos permite poner en tela de juicio los patrones de interpretación del «ser» en la sociedad, el espacio y el tiempo. Ahora bien, el uso del artículo determinado (LA espera) es fundamental, puesto que no dirigiremos la atención en el hecho de esperar, sino en la dimensión existencial del ser en situación de espera. Para llevar a cabo esta investigación, nos ubicaremos especialmente en los mundos americanos, caracterizados por la amplitud, la variedad y la antigüedad de sus movimientos migratorios.

Palabras clave: mundos americanos; movilidades; espera; territorios; habitar.

Resum. Dels llocs d'espera als territoris de l'espera: Una nova dimensió de la geografia social?

Lluny de ser fluids, homogenis o lineals, els desplaçaments d'índole diferent que caracteritzen les societats contemporànies estan marcats per temps i moments, més o menys llargs, d'espera. El propòsit d'aquest article és analitzar com i per què aquests moments troben una traducció espacial relacionada amb interaccions socials específiques. Sobrepassar la noció tradicional de «llocs d'espera» per configurar nous «territoris de l'espera» ens permet posar en dubte els patrons d'interpretació de l'«ésser» a la societat, l'espai i el temps. Ara bé, l'ús de l'article determinat (L'espera) és fonamental, ja que no dirigirem l'atenció en el fet d'esperar, sinó en la dimensió existencial de l'ésser en situació d'espera. Per dur a terme aquesta investigació, ens ubicarem especialment en els mons americans, caracteritzats per l'amplitud, la varietat i l'antiguitat dels seus moviments migratoris.

Paraules clau: mons americans; mobilitats; espera; territoris; habitar. 
Résumé. Des lieux d'attente aux territoires de l'attente. Une nouvelle dimension de la géographie sociale

Loin d'être fluides, homogènes et linéaires, les déplacements de différents types qui caractérisent les sociétés contemporaines sont marqués par des temps et des moments, plus ou moins longs, d'attente. Le but de cet article est d'analyser pourquoi et comment ces moments s'inscrivent dans un espace où se développent des interactions sociales particulières. Dépasser la notion traditionnelle des «lieux d'attente " pour mettre en place des " territoires de l'attente" nous permet de questionner les schémas d'interprétation de "l'être" en société, dans l'espace et dans le temps. L'usage de l'article défini (L'attente) est ici fondamental car il ne s'agit pas de s'intéresser au fait d'attendre mais bien à la dimension existentielle de l'être en attente. Pour mener à bien cette enquête, nous nous situerons plus particulièrement dans les mondes américains caractérisés par l'ampleur, la variété et l'ancienneté de leurs mouvements migratoires.

Mots-clés: mondes américains; mobilités; attente; territoires; habiter.

\begin{abstract}
From waiting areas to waiting territories: A new dimension of social geography?
Far from homogeneous and linear flows, movements of different natures that characterize contemporary societies are marked by more or less long waiting moments and times. The purpose of this article is to analyze why and how these moments are part of a space where individuals and groups develop specific social interactions. Beyond the traditional notion of "waiting areas" we put forward the idea of "waiting territories", allowing us to question the patterns of "being" in society, space and time, and examine the existential dimension of living or inhabiting in a waiting situation. To carry out this investigation, we focus on American worlds characterized by the scope, variety and antiquity of their migrations.
\end{abstract}

Keywords: American worlds; mobilities; waiting; territories; inhabit.

\begin{aligned} & \multicolumn{2}{c}{ Sumario } \\ & Introducción 3. Hacer con el espacio y el tiempo \\ & 1. El territorio de la espera: ¿escenario o de la espera \\ & actor de las interacciones sociales? 4. Conclusión \\ & 2. Habitar los territorios de la espera: Referencias bibliográficas \\ & entre actores y autores \end{aligned}

\title{
Introducción
}

Los fenómenos de movilidad y desplazamiento se afirman como características principales de nuestras sociedades contemporáneas. Sin embargo, lejos de ser fluidos, homogéneos o lineales, estos desplazamientos están marcados por tiempos y momentos, más o menos largos, de espera. Su origen puede ser por razones técnicas, administrativas o políticas, y a menudo tales momentos encuentran una traducción espacial: hay territorios que acogen a estas sociedades en situación de espera. 
Analizar estos territorios de la espera y la multiplicidad de formas que revisten, calcular sus dimensiones, definir sus estatutos jurídicos, sus articulaciones con el espacio circundante, sus temporalidades específicas, así como la variedad de los procesos económicos y sociales que se despliegan en su marco - tal es el reto que se ha marcado desde 2011 un grupo internacional de historiadores, geógrafos, sociólogos y literatos reunidos bajo el acrónimo TERRIAT (Territoires de l'attente, 'Territorios de la espera').

Para tal investigación, nos enfocamos en los mundos americanos nacidos a lo largo del tiempo de desplazamiento (voluntario o forzado) de distintas comunidades. Durante siglos, tierra de refugio para perseguidos de todas las confesiones, luego Eldorado soñado por millones de inmigrantes, el continente americano es todavía el teatro de cuantiosos traslados humanos: campesinos que dejan sus pueblos para apilarse en ciudades insostenibles; indocumentados cruzando las fronteras del miedo; refugiados o damnificados que deben vivir en instalaciones precarias a raíz de un desastre «natural»; millones de automovilistas atrapados a diario en la trampa clásica de los embotellamientos urbanos, etc.

Este campo de estudio es innovador, porque se enfoca en espacios y en tiempos intersticiales en los cuales se experimentan los límites no solo de la sociedad, sino también del poder (tanto del estado como de todos los actores involucrados en el manejo de la espera) y, hoy en día, de la modernidad. Analizar esos lugares intermedios nos permite cuestionar los momentos de incertidumbre que prevalecen en una situación de transición entre un presente agotador, un futuro deseado y un pasado reprimido o idealizado.

Para llevar a cabo este análisis, resultará necesario, en primer lugar, definir la noción misma de territorio de la espera, considerándolo no sólo como un escenario, sino también como un actor con interacciones sociales específicas. Luego trataremos de ver lo que puede significar «habitar» un territorio de la espera, propuesta sumamente paradójica si consideramos que solo se trata de un momento (y un espacio) transitorio entre un punto de salida y un lugar de llegada. Esas reflexiones nos empujarán a cuestionar la dinámica y el valor de la espera para individuos, grupos y comunidades en proceso de movilidad y migración. Terminaremos, entonces, con los usos y las prácticas, tanto individuales como colectivas, de la espera, no solo desde el punto de vista de los que la sufren, sino también de los que saben o pueden aprovecharse de ella.

\section{El territorio de la espera: ¿̇escenario o actor de las interacciones sociales?}

Hasta ahora, tanto los historiadores como los sociólogos y los geógrafos han estudiado prioritariamente los flujos, los desplazamientos y las dinámicas sociales o espaciales, en lugar de estudiar los momentos y los espacios de estancamiento, agotamiento e inmovilidad. Sin embargo, como indicó Guy Di Méo en su libro Géographie sociale et territoires, las actividades sociales producen temporalidades específicas. Las formas temporales están estrechamente vinculadas a las formas espaciales de las construcciones sociales y deben tenerse en cuenta en el mismo movimiento de interpretación (Di Méo, 1998: 21). 
Más cerca del individuo, está el tiempo vivido, percibido, el tiempo de la experiencia sensorial y sensible. Cada individuo ha experimentado su plasticidad, su subjetividad, su capacidad de estiramiento, de parecer muy largo o muy corto según su disposición emocional o psicológica, su inversión personal, su actividad, su estatuto o el papel que está desempeñando en algún momento de su existencia. En situación de espera, el tiempo se extiende, se dilata, pero parece que el espacio se va reduciendo: ya no está a la altura de nuestras necesidades (o expectativas). La espera, por lo general, induce una sensación de encierro.

Basándose en los trabajos de Eric Dardel o Heidegger para profundizar los temas complejos de las relaciones entre espacio y tiempo (temática esencial cuando se trata de la espera), Di Méo no duda en afirmar que nuestra proyección en el espacio como seres psicológicos y sociales es la base de nuestra existencia. Pero esta proyección en el espacio es también una proyección en el tiempo, en un presente particular, en un momento singular de la duración. Di Méo define entonces el territorio según tres dimensiones que nos permiten entender cómo se pueden estudiar los territorios de la espera: todos los lugares frecuentados por el individuo (espacio de vida); las relaciones sociales que se tejen en su entorno (espacio social), y los valores psicológicos que se proyectan y se perciben en él (espacio vivido).

Siguiendo esta perspectiva analítica, los lugares de la espera deben ser considerados también como espacios producidos que materializan, durante un transcurso de tiempo incierto e indefinido, el campo de acción de los individuos y de los grupos. Se combinan, pues, con un espacio percibido y representado (integrando las modalidades de conocimiento o cognición de sus habitantes) y también con un espacio vivido condicionado por las modalidades de la existencia humana y por un conjunto (o un sistema) de prácticas socioespaciales.

Es así como, al tomar en cuenta la influencia del territorio sobre las interacciones sociales y la construcción de identidades (individuales y colectivas), es preciso pasar a un nivel superior del análisis socioespacial: la territorialidad. Por supuesto, no se trata de descartar las definiciones de la territorialidad relacionadas con el uso y las practicas del poder, tal como las plantearon Claude Raffestin (1980) o Sack (1986). Sin embargo, al enfocarnos en la dimensión existencial de la espera, una de las propuestas teóricas que más perspectivas puede abrir es la de Mercedes Bresso y Claude Raffestin cuando califican la territorialidad como «la estructura latente de la vida cotidiana, la estructura relacional, no percibida o poco percibida, de lo cotidiano» (Bresso y Raffestin, 1982: 186).

Con todo, si bien el territorio, con sus reglas, sus normas y sus códigos, es el espacio por excelencia donde se forjan las relaciones de poder y donde se desarrollan las interacciones sociales, nos toca distinguir entre lo que entendemos por «lugar» de espera y por «territorio» de la espera. En su libro L'espace social: Lecture géographique des sociétés, Pascal Buléon y Guy Di Méo expresaban que «si bien el lugar se define principalmente por funciones y prácticas individuales y sociales, el territorio expresa más bien un sistema de representación, una ideología y una autoridad» (Di Méo y Buléon, 2005: 88). El problema sería, entonces, saber hasta qué punto los lugares y los espacios de la espera pueden 


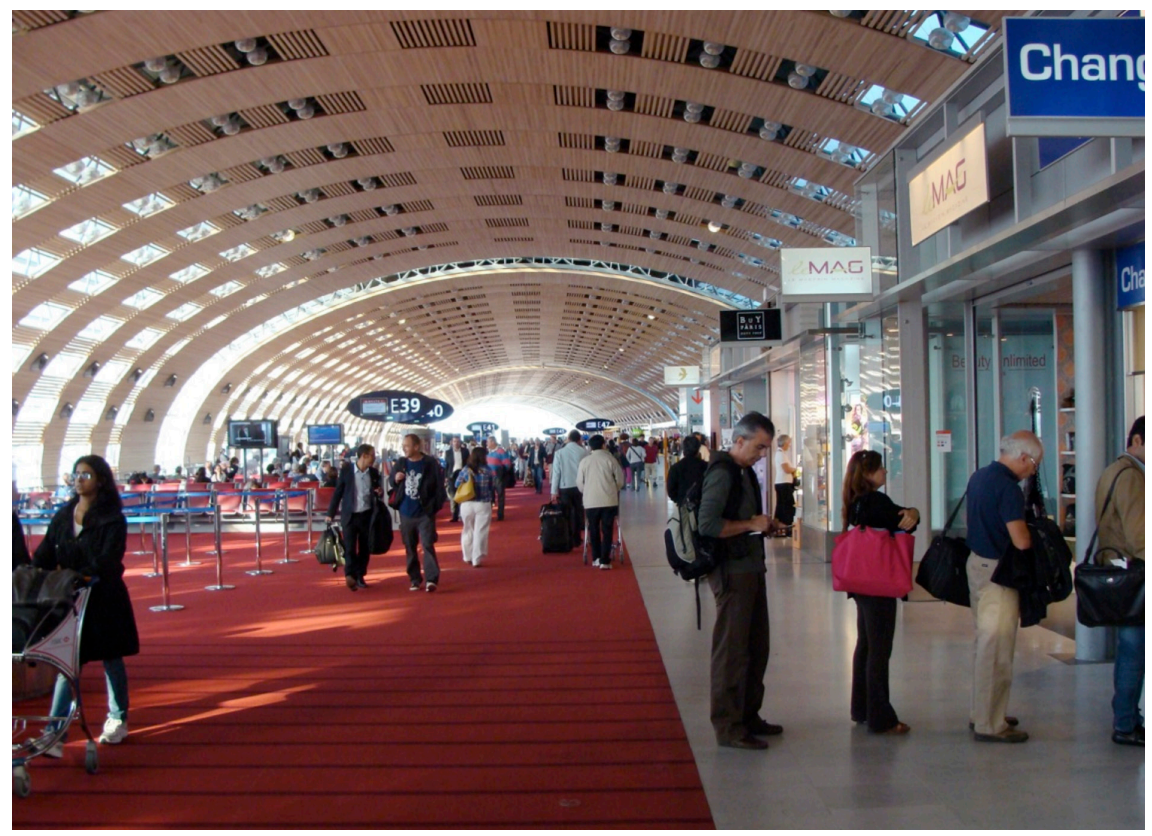

Figura 1. Sala de espera en la zona internacional de Roissy 2 (Francia), espacio funcional y genérico cuyo modelo se repite ad líbitum por todos lados.

Fuente: foto del autor (2011).

ser considerados como territorios en los cuales resultaría posible identificar no solamente relaciones de poder, sino también apropiaciones individuales o colectivas y representaciones de una ideología, tanto físicas como simbólicas.

Cabe decir, al respecto, que, según las representaciones tradicionales de la espera, los lugares dedicados a esta actividad (o a esta supuesta no-actividad) se asemejan a los «no-lugares» definidos en su tiempo por Marc Augé (1992). En efecto, entre los no-lugares mencionados por el antropólogo, varios están directamente relacionados con los procesos contemporáneos de movilidad y migración: no solamente los campos de refugiados o las chabolas temporales edificadas por los migrantes en su camino hacia nuevos y frustrantes paraísos terrenales, sino también todos los puntos de tránsito, las garitas internacionales, los clubes de vacaciones o las cadenas hoteleras que repiten la misma estructura, el mismo diseño de interiores, los mismos paisajes estereotipados; idénticos, en este sentido, a las latas de sopa Campbell, pintadas y multiplicadas por Andy Warhol.

Sin embargo, basta observar cómo los pasajeros que están esperando su vuelo en una terminal aeroportuaria anónima logran organizar temporalmente su espacio vital para darse cuenta de que, incluso en una escala espacial y temporal «micro», las cuestiones territoriales siguen conservando todo su sentido (figura 1). Al colocar cuidadosamente bolsas y maletas en 
sus alrededores, establecen límites, crean márgenes, abren y cierran puertas y escotillas. En este dispositivo, las familias gozan de un arma formidable: los niños. Por sus gritos, sus carreras ruidosas, sus lágrimas, expulsan automáticamente de sus bastiones autoproclamados todos los recién llegados. Al derramar, en el suelo y sobre los asientos de su alrededor, montañas de migajas, manchas de helados y de ketchup, marcan su territorio de manera tal vez inconsciente, pero siempre muy eficaz —incluso después de su partida.

Esta apropiación de un espacio público con sus reglas especiales es el tema de la divertida y angustiante película de Steven Spielberg The Terminal (2004), cuyo protagonista principal, Víctor Navorski (Tom Hanks) no puede salir del aeropuerto John-Fitzgerald Kennedy (y tampoco volver a casa) por razones diplomáticas y políticas. Prisionero de esta cárcel administrativa, el desdichado viajero tiene que conformarse con su nuevo lugar de vida, pero, paulatinamente, consigue armar, física y simbólicamente, un espacio adaptado a sus deseos y necesidades.

Es así como la propuesta del grupo TERRIAT de añadir a los bien conocidos «lugares de espera» unos "territorios de la espera» aún en proceso de evaluación y evolución científica, tiene como meta poner en tela de juicio los patrones de interpretación del modo de «ser» en la sociedad, el espacio y el tiempo. Desde luego, el uso del artículo determinado (LA espera) es fundamental para nuestro enfoque teórico y metodológico. No nos basamos en el hecho de esperar, sino en la dimensión existencial del «ser» en situación de espera - una dimensión existencial que no pretende la universalidad, sino que depende de la cultura compartida por los individuos y los grupos en posición de espera.

La espera es, entonces, lo que puede dar sentido no sólo al espacio, sino también a las personas y a los grupos que se encuentran, deliberadamente o de manera involuntaria, en una situación donde el tiempo queda suspendido. La aparente paradoja de esta propuesta radica en el carácter teóricamente transitorio, a veces volátil o efímero, del proceso de espera. ¿Podemos, pues, considerar como verdaderos territorios esos espacios frecuentados por sujetos y actores que se saben o se quieren en situación de tránsito, es decir, en un tiempo que no durará?

Este es el problema de la identificación y la territorialización de dichos actores, así como de la construcción de las prácticas sociales inducidas por el tiempo de espera, tal como recuerdan, al pasajero cansado de esperar, las pinturas murales ubicadas en la central de autobuses de Tarragona: «Mientras esperamos, la vida pasa. Hay tantas maneras de matar ese tiempo como de vivirlo intensamente. En ese lapso, podemos reflexionar, observar, jugar, dibujar, y un largo etcétera. Yo soy de los que se dedican a observar, reflexionar y dibujar...» (figura 2). 


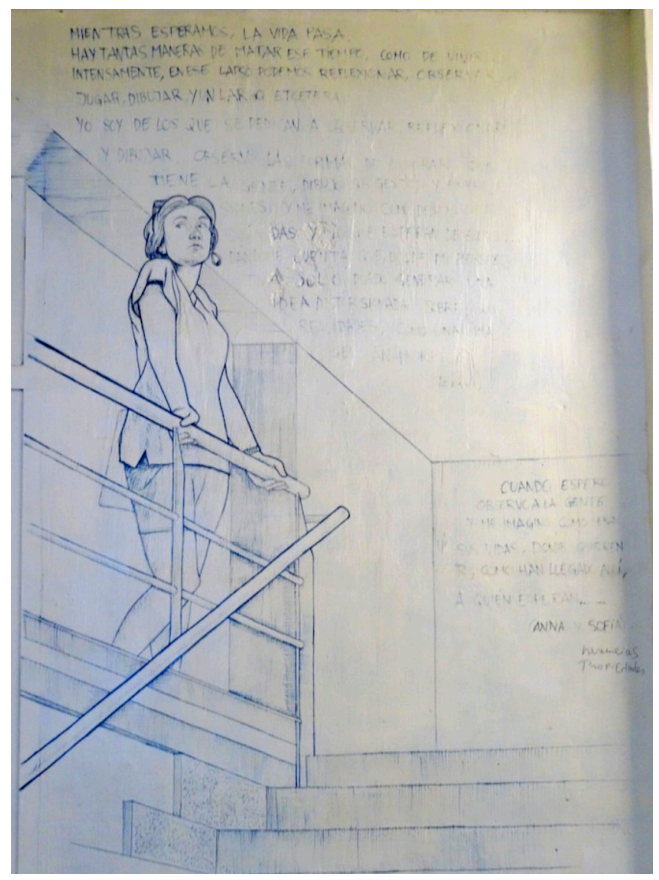

Figura 2. Mural de la espera, central de autobuses de Tarragona.

Fuente: foto del autor (2014).

\section{Habitar los territorios de la espera: entre actores y autores}

Para entender mejor este proceso, parece entonces necesario referirse a los trabajos en psicogeografía de Abraham Moles, quien hablaba de las diferentes "capas del ser humano" para identificar las modalidades de acceso de los individuos al mundo exterior, desde lo más íntimo (su cuerpo, su habitación) hasta lo más abierto y público (la región). Es así como los lugares de espera pueden materializar una apropiación funcional o virtual (y por un tiempo limitado) de un espacio público por una memoria privada — siguiendo el esquema general propuesto por Moles: «C'est l'idée que ce lieu particulier est marqué par ma présence, par mes actes, par mes objets ou les êtres que j'y ai installés, qui le rendent à mes yeux à nul autre pareil» (Moles, 1995: 173).

En la actualidad, es sin duda en el concepto de habitar donde la geografía social debe buscar nuevos caminos de investigación que puedan desarrollarse de manera tal vez paradójica en el marco de un estudio sobre los territorios de la espera. De hecho, como dice Thierry Paquot en un artículo titulado «Habitat, habitation, habiter, ce que parler veut dire " ('Hábitat, habitación, habitar, lo que hablar quiere decir'), habitar no sólo significa vivir en una casa, sino también fomentar relaciones con la sociedad y el mundo: 
La palabra habitación viene del latín "habitatio" y expresa el hecho de habitar, la vivienda o morada. Como sugiere su etimología latina, la palabra habituar ha significado vestir durante mucho tiempo, pero «habituari» también significa tener tal manera de ser, y esta manera de ser depende en gran medida de la ropa [...] El verbo habitar es tomado del latín «Habitare» (tener a menudo) como lo precisa su derivado «habitudo», que corresponde al francés "habitude» [hábito o costumbre en español], pero esta palabra también significa "permanecer». [...] Esas informaciones nos muestran cómo la palabra habitar es rica, que su significado no puede limitarse a la acción de morar o de ser alojado, pero que desborda por todos lados tanto la habitación como el ser, hasta el punto que no se puede pensar el uno sin el otro [...] Esta es la conclusión establecida por el filósofo y sociólogo Henri Lefebvre (1901-1991), cuando introdujo este concepto en la sociología urbana francesa durante los años sesenta, en gran parte inspirado por el filósofo alemán Martin Heidegger ${ }^{1}$. (Paquot, 2005: 48) (Traducción propia del original)

Existe entonces una relación estrecha, pero disimulada por la deriva de las palabras, primero entre el hábito y la ropa (como una señal de estado y estatus), luego entre la ropa y la costumbre (como forma de ser en un «habitus» simbólico) y, finalmente, entre el hábito y el hábitat, ya que la habitación (la vivienda) es el lugar donde el ser humano suele permanecer. El hogar (habitación) como lugar donde vivimos es el lugar por excelencia de la costumbre (hábito), como lo muestra el vínculo que podemos establecer entre morar (residir, habitar) o morada (vivienda) en español y el latín "mos-moris» (hábitos, costumbres en español).

Como lo recuerda Thierry Paquot, según la perspectiva fenomenológica de Martin Heidegger, habitar significa «estar en el mundo», o sea, participar activamente en el ecúmene. Esto es, en última instancia, una posición cercana a lo que expresaba Merleau-Ponty en su obra maestra, Fenomenología de la percepción, en la cual el filósofo francés planteaba que el espacio solo vale porque está percibido por la persona que lo habita —y está habitado por el que lo percibe, siendo la percepción la primera experiencia sensorial del ser humano.

El problema es que, en este sentido, el concepto de habitar puede aparecer demasiado incluyente para ser eficiente en el marco de un estudio sociogeográfico e histórico directamente relacionado con la idea de territorio. Además, ¿qué pasa con los territorios de la espera que, por su carácter generalmente transitorio, no corresponden a la idea de morar y permanecer?

De hecho, si bien los seres humanos se definen en parte por los lugares en donde viven, Olivier Lazzarotti señala al respecto que los individuos ya no se identifican con un sólo lugar, sino que están caracterizados por una multiplicidad de lugares que se ubican en una perspectiva creciente de movilidad — lo que él llama «la sociedad de los habitantes móviles» (Lazzarotti, 2006: 91), proceso que Mathis Stock ha bautizado como «el habitar politópico» (Stock, 2006). Esta multiplicidad

1. Como decía Henri Lefebvre en su prefacio de L’habitat pavillonnaire: «QQué quieren los seres humanos, por naturaleza seres sociales, en el habitar? Quieren un espacio flexible, apropiable, adaptado tanto a la vida privada como a la vida pública, la ciudad y el paisaje» (Lefebvre, 1966: 22). 
de lugares corresponde también a una multiplicidad de escalas geográficas o temporales y a una multiplicidad de identidades, tanto individuales como colectivas.

Haciendo hincapié en la movilidad como una de las condiciones modernas de las formas de habitar, Mathis Stock no dudó en proponer el concepto de «habitus mobilitaire» (Stock, 2004), basado en la capacidad de los individuos de hacer frente a lugares que les son ajenos (y tal vez extraños) para volverlos familiares —un proceso de apropiación del espacio y de territorialización que deben llevar a cabo los inmigrantes en situación de espera, sobre todo cuando la espera se prolonga.

Con todo, en el campo más específico de las migraciones, los geógrafos y sociólogos debemos entender cómo las sociedades de migrantes conforman territorios dedicados a la espera, una espera de duración muy variable — desde la simple parada hasta una morada de varios meses en una ciudad fronteriza, sin olvidar la llamada "migración por etapas» (step migration), tal como Laurent Faret la estudió en sus trabajos sobre los migrantes mexicanos que se fueron a los Estados Unidos (Faret, 2003: 61).

Pero el habitar no es un hecho, sino un proceso. Como lo recuerda Jacques Levy, es «una virtualidad, un horizonte, un futuro» (Lévy, 2012). Esta propuesta teórica nos acerca a nuestra manera de ver el territorio de la espera como un lugar de tensión entre el presente y el futuro. La obra Habiter: La condition geographique, de Olivier Lazzarotti, abre numerosas perspectivas al respecto cuando afirma, por ejemplo, que: «l'habiter repose sur l'idée qu'au croisement du "où l'on est" et du "comment l'ont y est", se trouve le "qui l'on est" ou, plus précisément, la part géographique de ce "qui l'on est", autrement dit, la part de géographie qui entre dans l'élaboration de l'identité globale des hommes mais qui, aussi, participe à sa construction» (Lazzarotti, 2006: 21).

También es el punto de vista del libro editado por Thierry Paquot, Michel Lussault y Chris Younes: Habiter, le propre de l'humain (Habitar, la esencia de lo humano), cuyos autores hacen resaltar que, más allá del sentido común y corriente (vivir, permanecer en una casa, en un barrio o en una zona particular del espacio), la palabra habitar se refiere no sólo a la relación que el ser humano mantiene con el escenario de su existencia, sino también a la relación, constantemente renovada y a veces conflictiva, que establece con su entorno y con el mundo - conjunto de relaciones e intercambios que debemos estudiar de manera antropológica.

Para entender mejor cómo ubicar los territorios de la espera en la problemática más general del habitar, podemos ver, al respecto, las reflexiones de Michel Agier sobre los campos de refugiados, esos lugares de espera que, conforme va pasando el tiempo, se convierten en territorios de la espera en los cuales se conforman verdaderas identidades colectivas (Agier, 2008: 31). En Les camps aujourd'hui, un présent qui n'en finit pas, el antropólogo apunta que los campos de refugiados tienen, al principio, una forma precaria (como lugares de espera), pero que tienden a organizarse para conseguir una condición relativamente estable hasta convertirse en territorios de los cuales realmente se han apropiado sus habitantes (Agier, 2007). En las peores condiciones, el tiempo y la necesidad que nos impulsan a habitar el espacio de manera tanto física como simbólica nos empujan a "conformarnos» o a «arreglarnos con» el espacio: 
«Aquí, los refugiados se transforman, al cabo de dos o tres años, en habitantes, y luego se convierten en ciudadanos de una ciudad desnuda» (Agier, 2007: 99).

Ahora bien, el enfoque sensible, fenomenológico y existencial de los lugares que se desprende de este estudio de las formas de habitar el espacio de vida conduce a Olivier Lazzarotti a hablar del individuo no sólo como actor, sino también como el autor de su geografía - es decir, de su inclusión en el espacio-. Este concepto de «autor», inspirado por Michel Foucault (1971), nos permite comprender mejor cómo el habitante de un lugar (incluso si sólo lo habita de manera provisional, sabiendo o esperando que su tiempo de residencia sólo será transitorio) puede inscribirse en dicho lugar de manera a la vez singular y sintética a partir de las herramientas que comparte con los demás —o, al menos, con el grupo al cual pertenece (Lazzarotti, 2006: 228-229).

En cierta forma, podríamos decir que el habitante es el autor intérprete de un territorio específico cuya amplitud, tanto espacial como simbólica, depende de sus capacidades reales de acción —es decir, de su capital social y cultural.

Los barrios de desplazados que esperan volver a su lugar de origen a veces desde varias décadas pueden ser un buen ejemplo de este tipo de proceso. Es el caso de la comuna de la Pintana, en la zona metropolitana de Santiago de Chile, donde, a finales de la década de 1970, miles de habitantes pobres fueron trasladados en el marco del programa llamado "Erradicación de la pobreza». Según los funcionarios de la comuna que tuve la oportunidad de entrevistar ${ }^{2}$, los ancianos siguen votando en su comuna de origen (Vitacura, Los Condes, Huechuraba, etc.), porque todavía esperan «volver a casa». La Pintana se ha convertido, para ellos, en un territorio de la espera y la desesperación, puesto que no echaron sus raíces en esta comuna de exilio. En realidad, habitan el espacio que les corresponde por fuerza, pero no están habitados por el mismo - para usar la terminología de Heidegger sobre quien establece una relación ontológica entre el individuo y su espacio de vida.

Es una perspectiva que podemos experimentar de manera heterodoxa con la historieta Demain, demain (Mañana, mañana), de Laurent Maffre, basada en encuestas sociológicas realizadas en la década de 1960 por la investigadora Monique Hervo en los suburbios de Nanterre (comuna del oeste de París). Esta impresionante narración gráfica evoca el mundo de los trabajadores argelinos que migraron a Francia durante las décadas de 1950 y 1960 para participar en la reconstrucción y en la modernización de un país que estaba involucrado en una guerra colonial sangrienta para conservar sus posesiones en el norte de África.

Héroe involuntario de una epopeya miserable, Kader tuvo que abandonar su pueblo con la esperanza de ganar suficiente dinero en Francia para mandar remesas a su esposa y a sus dos hijos. Cuando, por fin, su familia logró trasladarse a París, el mismo Kader sólo pudo alojarla en una casucha insalubre cuyos muros débiles no constituían ningún obstáculo para las ratas.

En su relato, Laurent Maffre lleva a la escena una espera multidimensional y multilocalizada con idas y vueltas permanentes entre el presente y el pasado,

2. Entrevista con Rolando, miembro de la municipalidad, 20 de junio de 2012. 


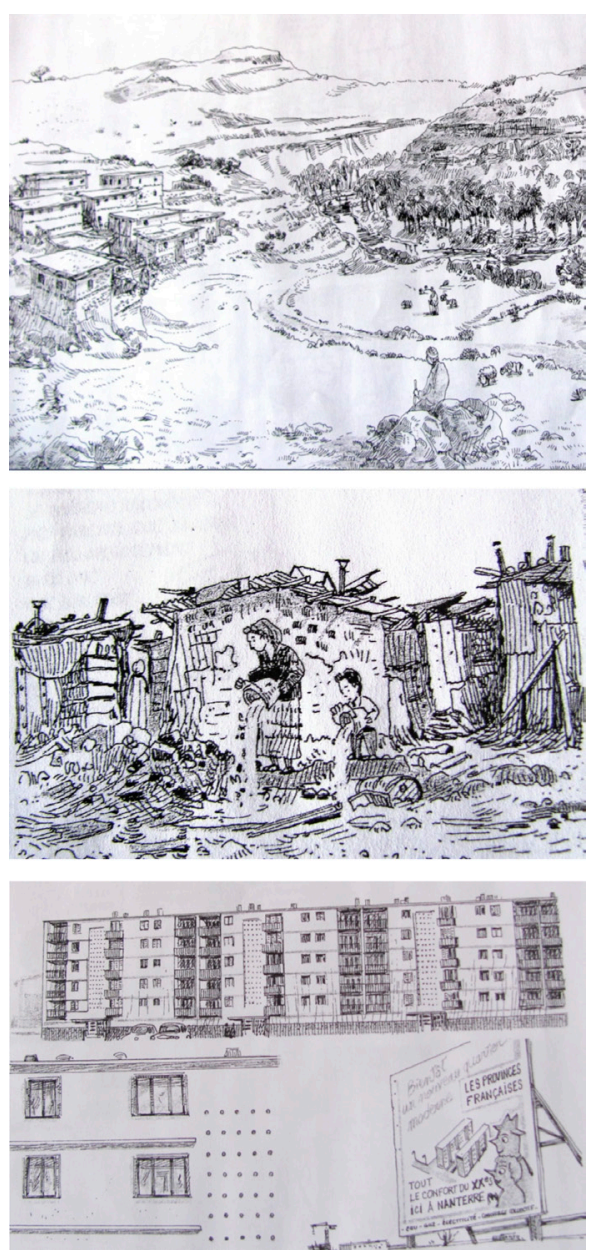

Figura 3. Entre el recuerdo y la nostalgia del pueblo abandonado y la ilusión de un futuro mejor, las familias de los migrantes argelinos tienen que conformarse con un presente insostenible.

Fuente: () Laurent Maffre: Demain, demain.

entre Nanterre y Argelia, tal como lo ha dibujado Abdelmalek Sayad en su obra maestra, La double absence ( $L a$ doble ausencia), síntesis de veinte años de investigación sobre los migrantes argelinos radicados en Francia: la espera de las mujeres que permanecieron en el pueblo y que viven con la esperanza de poder escaparse de allí; la espera de los maridos que toman sus fuerzas de la memoria y la nostalgia; la espera de las familias reunidas cuyo único deseo es huir del suburbio en donde están alojadas para trasladarse hacia un verdadero hogar — quizás un apartamento en el gran conjunto de vivienda social que se construye al lado de sus chabolas (figura 3). 
Pero, mientras tanto, todos deben «arreglárselas» con este territorio estigmatizado y estigmatizante. El presente de Kader y Soraya queda atrapado entre un pasado invasor y un futuro incierto, siguiendo la lógica trazada por $\mathrm{Yi}-\mathrm{Fu}$ Tuan en su libro Espace et lieu: La perspective de l'expérience, en donde analiza las formas y modalidades de cómo los individuos, dentro de un grupo y una cultura, perciben y construyen su realidad topológica por medio de un flujo continuo de alimentación simbólica entre la memoria (de lugares anteriores) y la anticipación o proyección hacia los lugares próximos.

Es así como la casita sórdida de la familia se ilumina con objetos e imágenes que recuerdan a la patria abandonada ${ }^{3}$. Se trata de una manera de domesticar o amansar un lugar hostil, percibido y experimentado como un mero paréntesis en el transcurso de una vida marcada por el desarraigo. El título de la obra de Laurent Maffre, Demain, demain (Mañana, mañana), expresa, entonces, la ambigüedad de un concepto, la espera, que suele combinarse con otra dimensión psicológica y social del ser humano ubicado entre dos momentos de su vida: la esperanza. De ahí que el lugar de espera tome un significado particular y se convierta en una parte esencial del estudio: no es sólo una escena o un cuadro donde se mueven los actores, sino un componente esencial del proceso estudiado.

En síntesis, podríamos decir que si bien los lugares son lo que hacemos de ellos, también hacen de nosotros lo que somos.

\section{Hacer con el espacio y el tiempo de la espera}

Estos tiempos «muertos» en el camino de los migrantes, viajeros o individuos en situación de movilidad, pueden resultar de trabas administrativas y barreras políticas, pero suelen también ser la consecuencia de diferentes prácticas y técnicas de desplazamiento (cambios de medio de transporte, paradas, averías, etc.). Al lado de los lugares diseñados de manera institucional para organizar la espera de los grupos que se mueven (salas de espera, albergues, centros de retención administrativa, etc.), pueden, entonces, surgir territorios «inesperados» de la espera cuya existencia depende de las interrupciones y de los bloqueos que suelen impactar en cualquier tipo de traslado. Esos territorios se construyen desde abajo a partir de las prácticas de los mismos individuos que logran apropiárselos de manera provisional o temporal —y a veces efímera-, cualquiera que sea la escala de estudio.

Es el caso, por ejemplo, de los embotellamientos que afectan diariamente, y con un ritmo bien conocido, la red viaria de las grandes metrópolis. Al trabajar sobre las temporalidades y los ritmos de la espera en situaciones de movilidad, es preciso devolverle al espacio el lugar que le corresponde en la gestión

3. Es una práctica generalizada en los hogares de todos los migrantes, como lo recuerda Frida Calderón Bony en sus estudios sobre los habitantes de Patambán (Michoacán, México) que cruzaron la frontera en busca de mejores condiciones de vida en los Estados Unidos (Calderón, 2010). 
colectiva o individual del tiempo social. De hecho, el espesor del tiempo así les otorga más consistencia a los lugares. El embotellamiento aparece, entonces, como un revelador de las contradicciones de un sistema supuestamente basado en la movilidad de los individuos, símbolo absoluto de la modernidad contemporánea. El lugar del atasco se convierte en un espacio donde pueden desarrollarse nuevas interacciones sociales, no sólo entre los conductores y sus pasajeros, sino también entre los ocupantes de los vehículos y sus vecinos, tal como lo cuenta Julio Cortázar en su novela corta La autopista del sur (1966), o entre los automovilistas y las personas exteriores que los rodean (peatones, vendedores ambulantes, etc.).

$\mathrm{Al}$ igual que en todos los lugares donde la espera impone una nueva gestión del tiempo, se construye temporalmente una sociedad efímera, basada en el intercambio de sentimientos relacionados con el aburrimiento, el interés, el cansancio, la ira o el conflicto, según modalidades muy peculiares, ya que está organizada desde los automóviles, o sea, lugares privados, cercados y cerrados, inmovilizados en un espacio público (la calle).

Siguiendo esta perspectiva, la idea de Mathis Stock de «hacer con el espacio» (o «arreglarse con el espacio») abre muchas pistas novedosas para trabajar sobre la noción de espera y su relación con el territorio. Por tanto, resulta imprescindible estudiar las prácticas que permiten, a los individuos y a los grupos sociales, conformarse con un lugar, utilizarlo y darle un nuevo sentido "cualquiera que sea la intención, la situación, la corporalidad, la movilidad en que están involucrados» (Stock, 2012: 57-58).

En el caso de los territorios de la espera, sin embargo, no sólo se trata de arreglarse con el espacio, sino también con el tiempo, puesto que, en este sistema, todo depende del lugar de espera (formal o informal), del tipo de espera (aceptado o sufrido) y del estatuto no sólo de las personas que están en situación de espera (de forma activa o pasiva), sino también de las personas que quieren, saben y pueden aprovecharse del tiempo de espera de las demás.

Puesto que se trata de espacios ordinarios que, por un tiempo (de espera), reciben de sus habitantes un sentido social y simbólico diferente de lo previsto por las instituciones, las autoridades o el poder, sería posible inscribir este análisis en la perspectiva de los «espacios otros», las famosas heterotopías ideadas por Michel Foucault en 1967:

Il y a également, et ceci probablement dans toute culture, dans toute civilisation, des lieux réels, des lieux effectifs, des lieux qui ont dessinés dans l'institution même de la société, et qui sont des sortes de contre-emplacements, sortes d'utopies effectivement réalisées dans lesquelles les emplacements réels, tous les autres emplacements réels que l'on peut trouver à l'intérieur de la culture sont à la fois représentés, contestés et inversés, des sortes de lieux qui sont hors de tous les lieux, bien que pourtant ils soient effectivement localisable. (Foucault, 1984)

Una situación de espera puede fomentar el uso inesperado de cualquier tipo de espacio, uso que viene a superponerse (transitoriamente) a su uso ordinario. 
En cierta forma, chocan aquí las tres dimensiones del espacio definidas en su tiempo por Henri Lefebvre: el espacio concebido (el de los dominantes), el espacio practicado (el de la cotidianidad) y el espacio vivido (en el cual los habitantes plasman sus propios imaginarios - a veces, en contra de la autoridad).

De ahí la paradoja central que debemos enfrentar: en las representaciones colectivas de la espera, el sujeto no actúa. Se le atribuye, de manera errónea, una función pasiva que no coincide con la realidad de las prácticas sociales desarrolladas en dichas situaciones. Aún más, es posible decir que, lejos de ser momentos sistemáticamente perdidos, los tiempos de espera pueden ser considerados como la materia prima de los actores que saben como aprovecharse de ellos.

Es el caso de los vendedores ambulantes que se ubicaron en el cruce fronterizo entre Tijuana (México) y San Diego (Estados Unidos), verdadero laboratorio de los dispositivos institucionales implementados para crear embotellamientos, fomentar la congestión y alargar los tiempos de espera de los viajeros ${ }^{4}$. Se trata, en efecto, de un punto de retención o de un filtro cuyo propósito es controlar el flujo de pasajeros entre México y Estados Unidos, para limitar el número de inmigrantes ilegales en busca de la tierra prometida.

Ahora bien, es preciso destacar que, en Tijuana, sólo hay dos puntos que permiten cruzar oficialmente la frontera: la garita internacional de Otay (principalmente utilizada para el tránsito de los productos elaborados en las plantas maquiladoras de la zona) y la de San Ysidro, por donde pasan anualmente casi 20 millones de vehículos y entre 40 y 50 millones de personas (en su mayoría, obreros y trabajadores que residen en México pero que trabajan en San Diego y en el sur del estado de California). Dependiendo de la época del año y de la hora del día, la cola puede durar hasta cuatro horas (figura 4).

A diferencia de los vendedores ambulantes tradicionales, que suelen operar en la informalidad más completa, los de San Ysidro deben, teóricamente, estar registrados por las autoridades y poseer su licencia. Es el caso de unos doscientos de ellos que trabajan por comisión para los dueños de las tiendas ubicadas a lo largo de las vías y que venden principalmente recuerdos típicos, artesanías, huchas de yeso, estatuíllas de barro (la Virgen de Guadalupe al lado de Super Mario y de la Santa Muerte), mantas, camisetas, ropa deportiva, etc., tal como apunta Jorge: «por ejemplo: serían ollas, calendarios aztecas, guitarras, hamacas, sarapes, todo lo tradicional que sea mejicano" ${ }^{5}$. Sin embargo, por lo menos, otros tantos actúan en la zona de manera ilegal, lo que puede dar lugar a tensiones con los vendedores «oficiales» y sobre todo con los policías, siempre dispuestos a extorsionar a los que «rehúyen» la ley.

Todas estas ventas están vinculadas a los ritmos particulares que rigen el tráfico de automóviles en la zona fronteriza. De hecho, hay fuertes amplitudes

4. La encuesta ha sido realizada a lo largo de cuatro años, durante los meses de septiembre de 2011 a 2014. La metodología se basó en la observación directa y en la grabación de entrevistas semidirigidas con los vendedores y las vendedoras de la línea fronteriza (56 en total). No apuntamos los apellidos, pero los nombres son reales.

5. Entrevista realizada el 27 de septiembre de 2012 con Jorge F., 33 años, originario de Sinaloa, vendedor en la línea fronteriza desde los 15 años. 


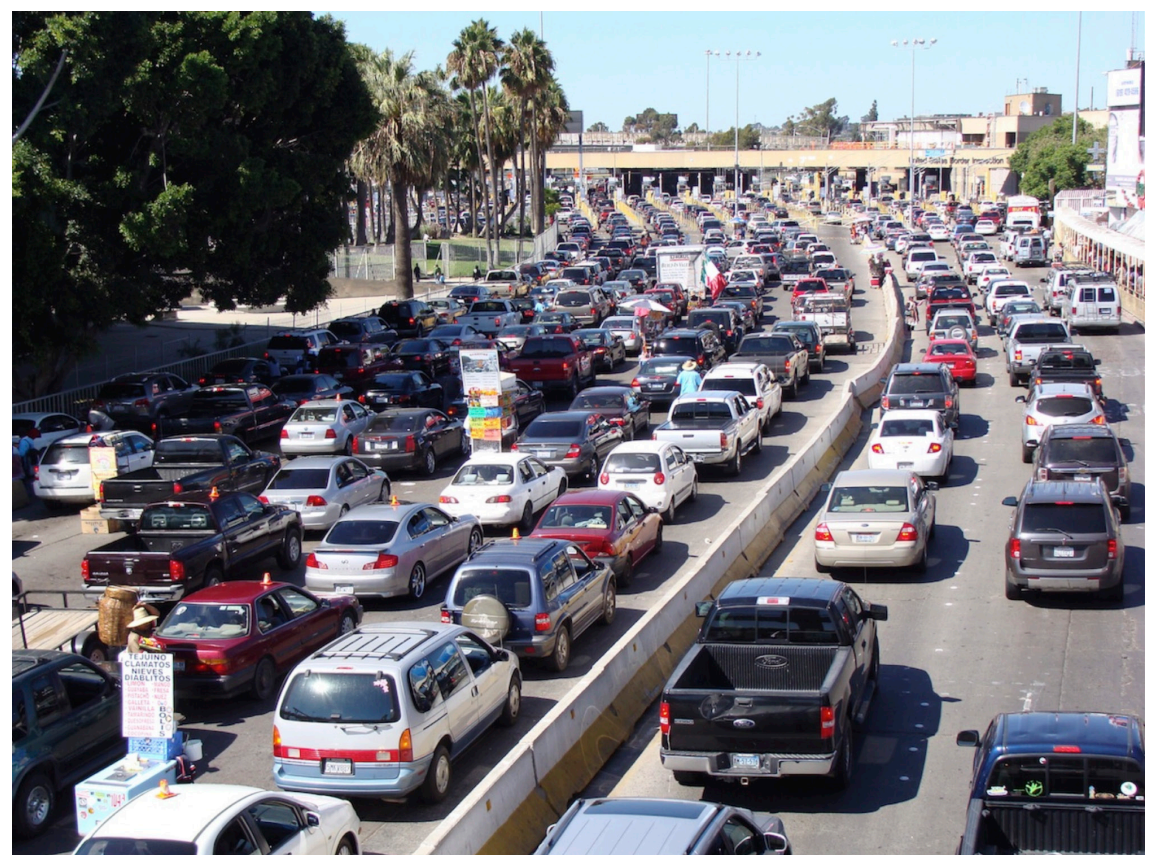

Figura 4. Filas de espera, río arriba de la garita internacional de San Ysidro, Tijuana, Baja California.

Fuente: foto del autor (2011).

diarias, semanales y estacionales que impactan directamente en el tiempo de espera de los conductores y, por tanto, en la actividad de los vendedores: «Y aquí mientras que haya fila y todo eso, pues, hay ventas, hay ventas y hay posibilidades de vender y..., se vende algo bien ${ }^{6}$.

Las horas punta de la mañana y de la tarde, cuando se alargan las filas de los coches en espera de cruzar la frontera, son los momentos de actividad más intensa para los vendedores de la línea, que, durante un promedio de diez horas de trabajo, pueden recorrer hasta diez o más kilómetros al día para alcanzar a sus clientes atrapados en un flujo casi inmóvil: «Caminando, en los carros, entre las filas hasta donde llegue, ir y venir, ir y venir, si te piden la mercancía de allá de la orilla, venir corriendo por ella pa' que no te ganen el cliente y así...» ${ }^{7}$. Para ilustrar su trabajo de manera más poética, José Ricardo usa una metáfora muy llamativa: «Aquí es como un río que corre, que corre

6. Entrevista realizada el 27 de septiembre de 2012 con Jaime, 40 años, originario de Guadalajara, vendedor en la línea fronteriza durante 15 años después de 20 años pasados en Estados Unidos.

7. Entrevista realizada el 27 de septiembre de 2012 con Martín, 42 años, tijuanense, vendedor en la línea fronteriza desde que tenía 12 años. 


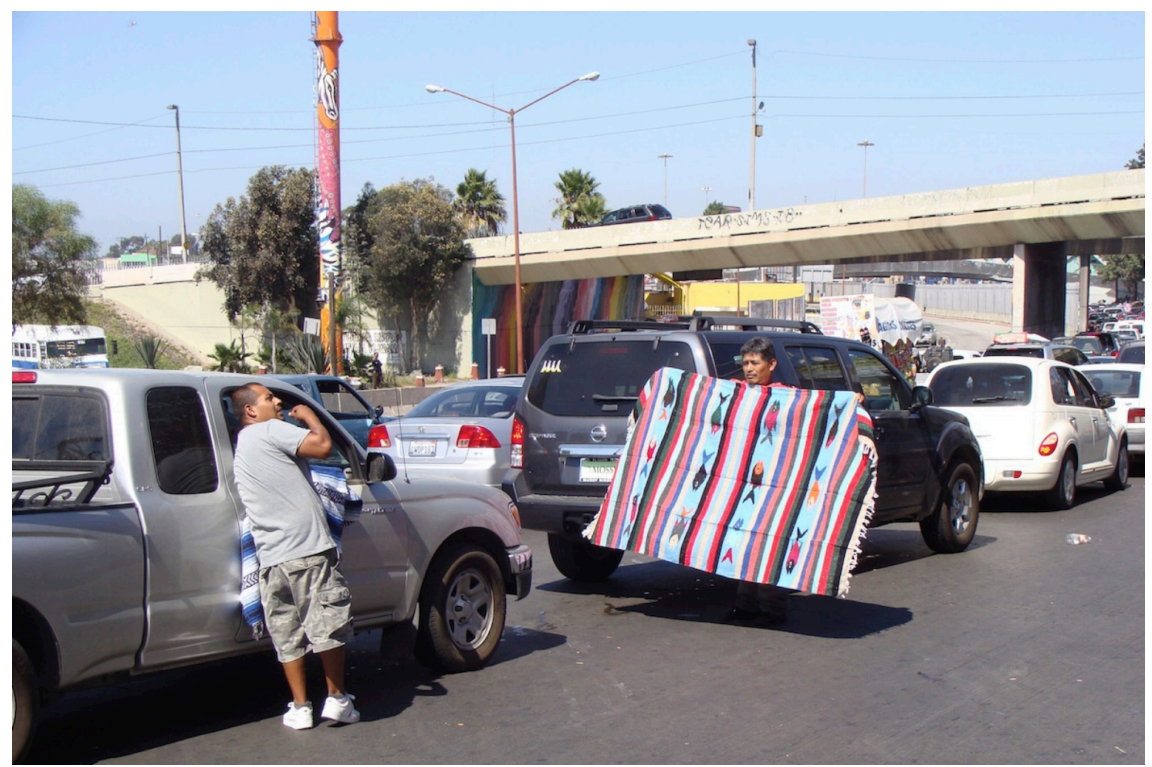

Figura 5. En el río de coches que fluyen lentamente hacia la garita internacional, los vendedores ambulantes han agarrado un pez metafórico en busca de sarapes coloridos.

Fuente: foto del autor (2012).

y uno es como un pescador que está pescando, que está pescando el pez» (figura 5) ${ }^{8}$.

Cabe destacar que este espacio de la espera, a pesar de su aparente anarquía espacial, está fuertemente territorializado en términos de poder, para mitigar los riesgos de enfrentamientos entre vendedores, tal como destaca José Ricardo:

Aquí el sistema es que cada local tiene sus vendedores, ¿no?, y cada vendedor tiene que vender en frente de su tienda. No se puede más por abajo ofrecer y no se puede más por arriba ofrecer porque hay una jerarquía, hay reglas que hay que llevar a cabo, sí, porque nada más yo quiero vender, quieren vender las demás personas. Luego se hace un relajo, un pleito se hace. Entonces, para no tener pleito y llevarnos bien, pues las personas, este..., tomamos esta determinación, pues estas reglas.

Además de este arreglo entre las tiendas y sus empleados, el espacio de venta de la línea fronteriza está dividido entre dos sindicatos que se han repartido el flujo de los vehículos:

8. Entrevista realizada el 5 de octubre de 2013 con José Ricardo, 27 años, originario de Michoacán, vendedor en la línea fronteriza desde el año 2012. 


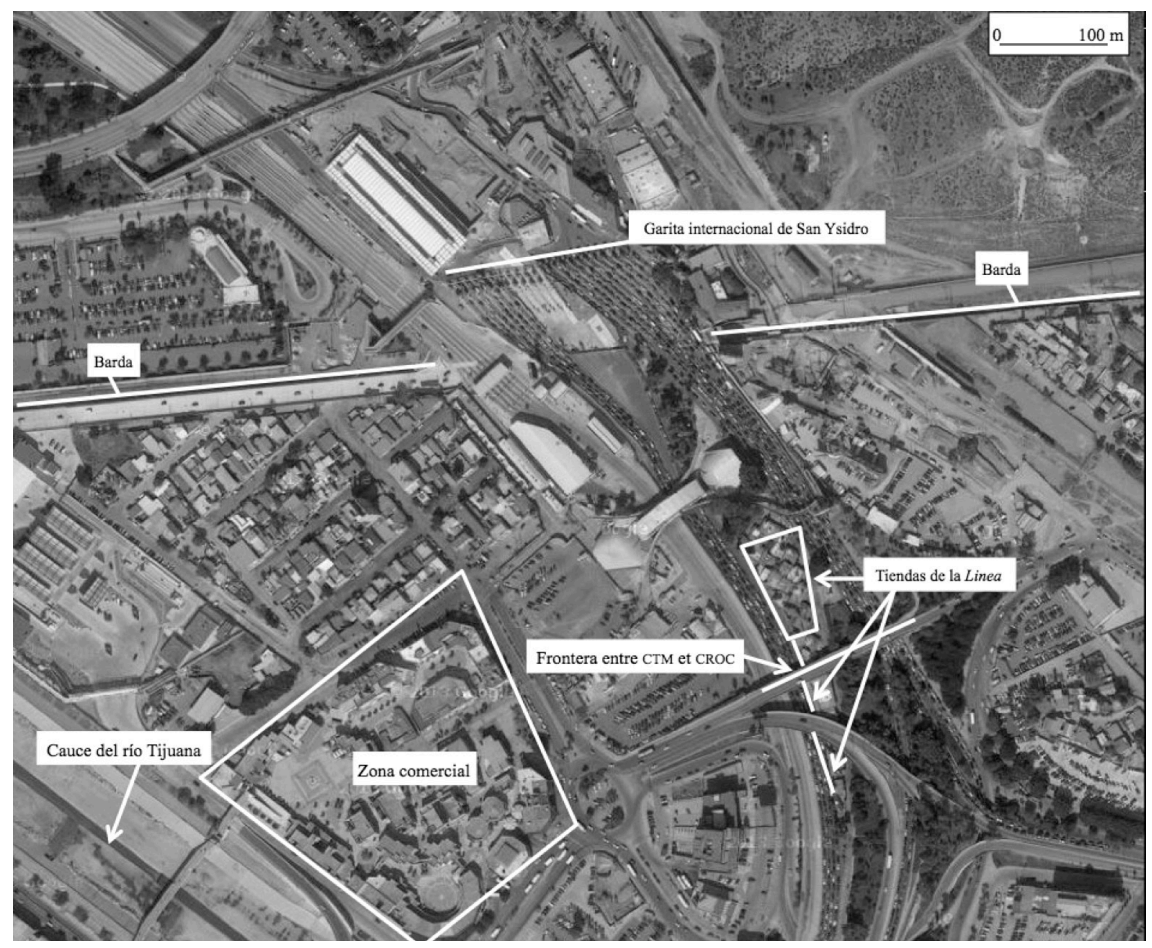

Figura 6. Organización del espacio fronterizo en la garita internacional de San Ysidro.

Fuente: imagen tomada de Google Maps procesada por el autor.

Entonces, este... Ahorita, estamos resintiendo como ves ya la fila, ya se va a acabar, ya está aquí, bajo aquí, ya no podemos pasar pa' allá, porque allá es otro sindicato, o sea allá hay otros que, o sea, del puente pa' acá... Somos un sindicato y de ahí no podemos bajar nosotros pa' abajo y ellos no pueden subir de allá pa' arriba9 .

De hecho, el primer puente al sur de la línea fronteriza sirve de confín entre los afiliados de la CTM (Confederación de los Trabajadores Mexicanos) y los miembros de la CROC (Confederación Revolucionaria de Obreros y Campesinos). Esta división significa mucho, porque, cuando el tiempo de espera es más corto, hay pocas filas y los de la CTM, ubicados más cerca de la garita internacional, tienen más posibilidades de vender sus productos. En cambio, cuando se necesitan dos horas o más para cruzar la frontera, los automovilistas y sus pasajeros hacen la mayor parte de sus compras con los de «arriba» (figura 6).

9. Entrevista realizada el 28 de septiembre de 2012 con Juan Manuel, 38 años, originario de Jalisco, vendedor en la línea fronteriza desde los 5 años. 
Esta apropiación del espacio, combinada con la conformación de una verdadera identidad colectiva, hace que podamos efectivamente hablar de un territorio de la espera y no de un simple lugar de espera. De hecho, muchos vendedores no dudan en decir que, para ellos, «la línea» es un verdadero lugar de vida donde desarrollan interacciones permanentes, tanto con sus "cuates» como con sus clientes. Es lo que hace resaltar Jorge F. cuando nos dice que «la línea es mi segunda casa ${ }^{10}$, con lo cual da más fuerza a la idea de que es posible habitar y ser habitado por un territorio de la espera.

\section{Conclusión}

Con todo, esos territorios de la espera no son los «no-lugares» ideados por Marc Augé en 1992, suponiendo que este tipo de espacio no puede conformar «ni identidad singular, ni relación, sino soledad y similitudes» (Augé, 1992: 130).

En dichos territorios, «lugares de un posible espacio público» (Agier, 2008: 102), si bien predomina un sentimiento de incertidumbre, identidades colectivas llegan a cuajar y a tomar forma en función de las necesidades y de las capacidades de los diferentes actores o autores y de las estrategias sociales que logran dibujar para enfrentar este tiempo incierto, cuya vigencia depende también de los dispositivos ideados «desde arriba» para su escenificación.

Es así como la apertura de una nueva carretera o la mejora de las condiciones de tráfico puede llevar a la desaparición o al desplazamiento de un territorio de la espera que fue productivo durante décadas. Es el proceso que estaba sucediendo en la garita de San Ysidro en octubre de 2014, durante mi último trabajo de campo. Después de un largo periodo de rehabilitación y renovación, han sido abiertas nuevas puertas en la línea fronteriza, lo cual ha provocado una drástica reducción de las colas en el sentido que va de México a Estados Unidos. En tan solo un mes, se desplomó el sistema de ventas que había funcionado durante décadas gracias al tiempo de espera de los automovilistas.

Muchas tiendas cerraron de manera provisional o definitiva (31 de las 65 ubicadas en los márgenes de las vías de acceso); los vendedores han comenzado a buscar nuevas fuentes de ingresos (en las maquiladoras de la Mesa de Otay, por ejemplo), y otros pasan el tiempo jugando a dominó y quejándose de su mala situación, sin saber cuando volverá el tiempo de las vacas gordas.

$\mathrm{Al}$ recordarnos que la impermanencia de las cosas es un dato fundamental de la condición humana, el caso del cruce fronterizo de San Ysidro nos enseña, así, que los territorios de la espera, diseñados por tal motivo o nacidos de circunstancias aleatorias, siguen marcados por la incertidumbre y la volatilidad - otra dimensión de la geografía social que debemos tomar en cuenta para analizar las relaciones ambiguas que cada sociedad mantiene con sus espacios de vida.

10. Entrevista realizada el 6 de octubre de 2013. 


\section{Referencias bibliográficas}

AgIER, Michel (2007). «Les camps aujourd'hui, un présent qui n’en finit pas». En: Paquot, Thierry; Lussault, Michel y Younès, Chris (dirs.). Habiter, le propre de l’humain. París: La Découverte, 89-101.

- (2008). Gérer les indésirables: Des camps de réfugiés au gouvernement humanitaire. París: Flammarion.

Augé, Marc (1992). Non-Lieux: Introduction à une anthropologie de la surmodernité. París: Le Seuil.

Bresso, Mercedes y Raffestin, Claude (1982). «Tradition, modernité, territorialité». Cahiers de Géographie du Québec, 68, 186-198.

Calderón Bony, Frida (2010). «L'espace d'habitation comme miroir identitaire: Le cas des migrants de Patambán (Michoacán, Mexique) aux États-Unis». Cahiers des Amériques Latines [en línea], 59, 57-78. <http://dx.doi.org/10.4000/cal.1109>

Cortázar, Julio (1966). «La autopista del sur». En: Todos los fuegos el fuego. Madrid: Alfaguara, 2007.

Di Méo, Guy (1998). Géographie sociale et territoire. París: Nathan Université.

Di MÉo, Guy y Buléon, Pascal (2005). L'espace social: Lecture géographique des sociétés. París: Armand Colin.

FARET, Laurent (2003). Les territoires de la mobilité: Migration et communautés transnationales entre le Mexique et les États-Unis. París: CNRS Éditions.

Foucault, Michel (1971). L'ordre du discours. París: Gallimard.

- (1984). "Des espaces autres» (conférence au Cercle d'études architecturales, 14 mars 1967). Architecture, Mouvement, Continuité [en línea], 5, 46-49. Dits et écrits 1984, tomo IV, texto 360 . <http://1libertaire.free.fr/Foucault12.html>.

Lazzarotti, Olivier (2006). Habiter: La condition géographique. París: Armand Colin.

- (2012). «Habiter, le moment venu, un moment donné...». En: Frelat-Khan, Brigitte y Lazzarotti, Olivier (dirs.). Habiter: Vers un nouveau concept? París: Armand Colin.

Lefebvre, Henri (1966). «Préface». En: Raymond, Henri; Haumont, Nicole; Dezès, Marie-Geneviève y Haumont, Antoine. L'habitat pavillonnaire. París: L'Harmat$\tan , 2001$.

LÉvy, Jacques (2012). «Habiter sans condition». En: Frelat-Khan, Brigitte y LazZAROTti, Olivier (dirs). Habiter: Vers un nouveau concept? París: Armand Colin, 25-34.

Merleau-Ponty, Maurice (1945). Phénoménologie de la perception. París: Gallimard, 1976.

Moles, Abraham (1995). "Vers une psycho-géographie». En: BaIlly, Antoine; Ferras, Robert y Pumain, Denise (dirs.). Encyclopédie de la géographie. París: Economica, 159-187.

PAQUOT, Thierry (2005). «Habitat, habitation, habiter, ce que parler veut dire...». Informations sociales [en línea], 3 (123), 48-54.

<www.cairn.info/revue-informations-sociales-2005-3-page-48.htm>.

Paquot, Thierry; Lussault, Michel y Younes, Chris (2007). Habiter, le propre de l'humain. París: La Découverte.

Raffestin, Claude (1980). Pour une géographie du pouvoir. París: Litec.

SACK, Robert (1986). Human Territoriality: Its theory an history. Cambridge: Cambridge University Press. 
SAYAD, Abdelmalek (1999). La double absence: Des illusions de l'émigré aux souffrances de l'immigré. París: Le Seuil.

Sтоск, Mathis (2004). «L'habiter comme pratique des lieux géographiques». Espaces Temps.net [en línea].

$<$ http://www.espacestemps.net/articles/habiter-comme-pratique-des-lieux-geographiques/>.

- (2006). "L'hypothèse de l'habiter poly-topique: Pratiquer les lieux géographiques dans les sociétés à individus mobiles». Espaces Temps.net [en línea].

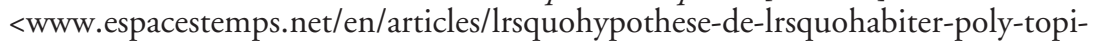
que-pratiquer-les-lieux-geographiques-dans-les-societes-a-individus-mobiles-en/>.

- (2012). «Faire avec l'espace: Pour une approche de l'habiter par les pratiques». En: Lazzarotti, Olivier y Frelat-Khan, Brigitte (dirs.). Habiter: Vers un nouveau concept? París: Armand Colin.

TARrius, Alain (1993). «Territoires circulatoires et espaces urbains: Différenciation des groupes migrants». Annales de la Recherche Urbaine [en linea], 59-60, 51-60. $<$ http://1libertaire.free.fr/Tgv03.html>.

Tuan, Yi-Fu (2006). Espace et lieu: La perspective de l'expérience. París: Infolio. 